Check for updates

Cite this: RSC Adv., 2019, 9, 18767

Received 15th February 2019

Accepted 8th June 2019

DOI: 10.1039/c9ra01173k

rsc.li/rsc-advances

\section{Microstructural characterization and film-forming mechanism of a phosphate chemical conversion ceramic coating prepared on the surface of $2 \mathrm{~A} 12$ aluminum alloy $\dagger$}

\begin{abstract}
Shuai Huang, Jian Wang, (D) Xiaowei Wei, Yuli Zhou, Lijun Wang and Jianjun Zhang
Phosphate chemical conversion (PCC) ceramic coatings on the surface of $2 \mathrm{~A} 12$ aluminum alloy substrate have been fabricated by a simple and inexpensive chemical conversion process in $\mathrm{CrO}_{3}-\mathrm{NaF}-\mathrm{H}_{3} \mathrm{PO}_{4}$ solution. Microstructure characterization showed that the average diameter of micro-pores and the thickness of the PCC ceramic coating were about $50 \mathrm{~nm}$ and $4 \mu \mathrm{m}$, respectively, and the ceramic coating was compact and uniform when the conversion time was $60 \mathrm{~min}$. Meanwhile, we found that the $\mathrm{PCC}$ ceramic coating mainly consisted of $\mathrm{AlPO}_{4}, \mathrm{AlOOH}, \mathrm{AlF}_{3}$, and a few amorphous phases $\left(\mathrm{CrPO}_{4}\right.$ and $\mathrm{CrOOH}$ ) via EDS, XRD, XPS analyses. TG-DSC results indicated that the PCC ceramic coatings had excellent thermal stability. Significantly, the adhesion strength $(178.55 \mathrm{~N})$ between the PCC ceramic coatings and 2A12 Al substrate was remarkably improved owing to the strong chemical bond between the PCC ceramic coating and 2A12 Al substrate and the increase of surface roughness. Furthermore, a lower corrosion current density $\left(1.382 \times 10^{-7} \mathrm{~A} \mathrm{~cm}^{-2}\right)$ and a higher corrosion inhibition efficiency (99.91\%) confirmed that PCC ceramic coatings had fantastic corrosion resistance because of the presence of crystalline $\mathrm{AlPO}_{4} / \mathrm{AlF}_{3} / \mathrm{AlOOH}$ and amorphous $\mathrm{CrPO}_{4} / \mathrm{CrOOH}$ as a barrier layer. Additionally, a possible film-forming mechanism of the PCC ceramic coating was proposed during the chemical conversion process, which could be divided into four stages: dissolution of 2A12 aluminum substrate and hydrogen evolution; crystallization of insoluble phosphates and formation of an amorphous phase; growth of insoluble phosphates and dissolution of PCC ceramic coatings; growth and dissolution of PCC coatings to dynamic equilibrium.
\end{abstract}

\section{Introduction}

In recent years, the biggest challenge of the transportation industry is the ever-increasing demand to decrease air pollution and energy consumption. Light-weight transport is considered ideal to reduce carbon dioxide gas emissions and to enhance the fuel economy. ${ }^{1-3}$ In aerospace applications, owing to the low weight, high specific strength and better formability of aluminum (Al) alloys, they become the best candidate material to replace steel towards the development of a light-weight airplane. Especially, the 2A12 $\mathrm{Al}$ alloys have been widely used in various parts of the airplane, such as skin of the airplane, bulkhead of the airplane, wing ribs of the airplane, wing spars of the airplane, rivet of the airplane and so on, which is due to their low density, high fracture toughness and high thermal conductivity. ${ }^{4-10}$ Unfortunately, $2 \mathrm{~A} 12 \mathrm{Al}$ alloys also have a few

School of Materials Science and Engineering, Xihua University, Chengdu 610039, People's Republic of China. E-mail: wangjianxhu@163.com

† Electronic supplementary information (ESI) available. See DOI: 10.1039/c9ra01173k undesirable properties, such as low corrosion resistance and low wear resistance, which seriously impede their further applications, especially for outdoor applications. ${ }^{11-14}$ Therefore, in order to solve these problems, surface modification is necessary for the practical application of 2A12 $\mathrm{Al}$ alloys.

Surface modification is regarded as the most effective and straightforward approaches to protect $\mathrm{Al}$ alloys, ${ }^{15}$ which including anodic oxidation ${ }^{\mathbf{1 6}, 17}$ and micro-arc oxidation, ${ }^{18,19}$ thermal spraying, ${ }^{20,21}$ electroplating, ${ }^{22,23}$ ion implantation, ${ }^{24,25}$ electroless plating, ${ }^{26,27}$ magnetron sputtering, ${ }^{28,29}$ laser processing $^{30,31}$ and chemical conversion treatment. ${ }^{32,33}$ Thereinto, chemical conversion treatment is considered as an ideal method, which shows advantages such as simple and suitability for the treatment of irregular surfaces. ${ }^{34-37}$ Moreover, chemical conversion treatment is not only economical, but also creates a useful protecting layer on the metal surface, which is required in some specially applications.

Chemical conversion coating is also called metal conversion coating, and it is an insoluble inorganic coating fabricated on the surface of steel, ${ }^{38}$ iron, ${ }^{39}$ magnesium, ${ }^{40}$ aluminum ${ }^{41}$ and their alloys via chemical conversion treatment without need for 
an additional electrical force and magnetomotive force. In recent decades, many scientists have focused on the formation mechanism of various types of chemical conversion coatings. Treverton and Davies ${ }^{42}$ first put up with a model of chromatephosphate coatings in 1977. Shanmugam et al. ${ }^{1}$ reported that the growth mechanism of iron-manganese phosphate composite coatings formed on the aluminum surface was dissolution of $\mathrm{Al}$ and a subsequent deposition of coating. Golabadi et al. ${ }^{43}$ demonstrated that $\mathrm{Ni}^{2+}$ and $\mathrm{Co}^{2+}$ could increase the corrosion resistance of the phosphate coating. Nevertheless, although chemical conversion coating has been investigated for many years, the phosphate conversion coating with excellent microstructure, corrosion resistance and high temperature resistance has not been reported to date.

In this work, we have prepared phosphate chemical conversion (PCC) ceramic coating on the surface of $2 \mathrm{~A} 12 \mathrm{Al}$ alloys via chemical conversion treatment. Moreover, the microstructure, elemental distribution, phase composition and thermal stability, adhesion strength and corrosion resistance of PCC ceramic coating were studied systematically. In addition, the formation mechanism of the ceramic coating was discussed in detail, which founded the basis for industrial production.

\section{Experimental section}

\subsection{Materials and coating preparation}

Square sample of $2 \mathrm{~A} 12 \mathrm{Al}$ alloys of size $40 \mathrm{~mm} \times 40 \mathrm{~mm} \times$ $1 \mathrm{~mm}$ was used as substrate material in our experiment, which was purchased from Asia Metals Co. Ltd., Sichuan, China. The chemical composition of 2A12 Al alloys was listed in Table 1. Before the chemical conversion treatment, the sample was degreased with $50-70 \mathrm{~g} \mathrm{~L}^{-1} \mathrm{NaOH}$ solution at $60{ }^{\circ} \mathrm{C}$ for $2 \mathrm{~min}$, and then rinsed with deionized water immediately. Afterwards, the sample was immersed in $60-80 \mathrm{~g} \mathrm{~L}^{-1} \mathrm{HNO}_{3}$ solution at room temperature for $2 \mathrm{~min}$, followed by rinsing with deionized water immediately. After pretreatment process, the coating was prepared by immersing the samples in the conversion bath (3$6 \mathrm{~g} \mathrm{~L}^{-1} \mathrm{CrO}_{3}, 3-6 \mathrm{~g} \mathrm{~L}^{-1} \mathrm{NaF}$ and $\left.20-40 \mathrm{~g} \mathrm{~L}^{-1} \mathrm{H}_{3} \mathrm{PO}_{4}\right)$ at room temperature for $10 \mathrm{~min}, 30 \mathrm{~min}$ and $60 \mathrm{~min}$, respectively, and then washed with hot deionized water at $45{ }^{\circ} \mathrm{C}$ for $1 \mathrm{~min}$. Finally, sample aging via oven drying at $45^{\circ} \mathrm{C}$ for $10 \mathrm{~min}$ prior to any characterizations and measurements. The schematic illustration of the fabrication process for PCC ceramic coating in different conversion time was shown in Fig. 1.

\subsection{Characterization and testing}

The surface morphology and cross-sectional morphology of PCC ceramic coating were observed via field emission scanning electron microscope (FE-SEM, FEI Inspect F50). The elemental composition was analyzed using energy dispersive spectrometer

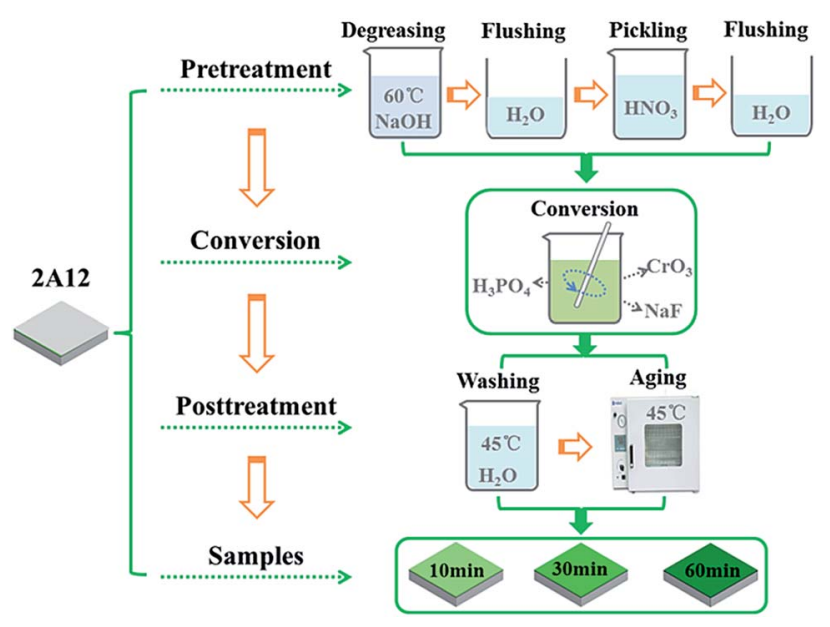

Fig. 1 Schematic illustration of the preparation process of PCC ceramic coatings.

(EDS, Octane super). Crystalline phase composition of PCC ceramic coating was examined by X-ray diffractometer (XRD, Bruker D8 Advance) using a Cu-K $\alpha$ radiation $(\lambda=0.154184 \mathrm{~nm})$, operated at $40 \mathrm{kV}$ and $100 \mathrm{~mA}$ at a scanning speed of $4^{\circ}$ per min from $20^{\circ}$ to $80^{\circ}$ of $2 \theta$. Meanwhile, the chemical composition of PCC ceramic was performed via X-ray photoelectron spectroscopy (XPS, Escalab $250 \mathrm{Xi})$ using Al-K $\alpha(1486.6 \mathrm{eV})$ as the source. The data were analyzed with XPSPEAK41 software. Furthermore, the thermal stability was studied via thermo gravimetricdifferential scanning calorimetry (TG-DSC, STA 449C) at a heating rate of $10{ }^{\circ} \mathrm{C} \min ^{-1}$ from $30{ }^{\circ} \mathrm{C}$ to $800{ }^{\circ} \mathrm{C}$ in argon atmosphere.

\subsection{Scratch test}

Adhesion strength of PCC ceramic coating was determined using a single automatic scratch tester (WS-2005, Zhongke Kaihua Technology Development Co., Lanzhou, China) equipped with a diamond indenter (cone apex angle of $120^{\circ}$ with a $200 \mathrm{~mm}$ tip radius). In the process of scratch test, the load was stepwise increased from 0 to $200 \mathrm{~N}$ at a loading rate of 100 $\mathrm{N} \min ^{-1}$, and the scratch length was $5 \mathrm{~mm}$.

\subsection{Electrochemical measurements}

The electrochemical characteristic and corrosion resistance of PCC ceramic coating were evaluated via potentiodynamic polarization tests and electrochemical impedance spectroscopy (EIS) in $3.5 \mathrm{wt} \% \mathrm{NaCl}$ aqueous solution using an electrochemical workstation with a conventional three-electrode cell. Thereinto, the sample with the exposure area of $1 \mathrm{~cm}^{2}$ was acted as work electrode, the saturated calomel electrode (SCE) was

Table 1 The chemical composition of 2A12 Al alloys

\begin{tabular}{llllllll}
\hline Elements & $\mathrm{Al}$ & $\mathrm{Cu}$ & $\mathrm{Mg}$ & $\mathrm{Mn}$ & $\mathrm{Si}$ & $\mathrm{Zn}$ & $\mathrm{Ti}$ \\
\hline Content (wt\%) & Balance & $3.8-4.9$ & $1.2-1.8$ & $0.3-0.9$ & $\leq 0.5$ & $\leq 0.3$ & $\leq 0.15$
\end{tabular}


used as reference electrode and platinum (Pt) electrode was used as auxiliary electrode. The stable open circuit potentials (OCP) were acquired through immersing into $\mathrm{NaCl}$ solution for $30 \mathrm{~min}$ before the test. Whereafter, the potentiodynamic polarization curve was examined to obtain the corrosion potential $\left(E_{\text {corr }}\right)$ and corrosion current density $\left(I_{\text {corr }}\right)$ at a scanning rate of $1 \mathrm{mV} \mathrm{s}^{-1}$ using extrapolation method. The EIS measurements were carried out with the sinusoidal perturbation amplitude of $20 \mathrm{mV}$ and frequency range from $10^{-2} \mathrm{~Hz}$ to $10^{5} \mathrm{~Hz}$.

\section{Results and discussion}

\subsection{Microstructure of PCC ceramic coatings}

Fig. 2 presented the surface morphologies of PCC ceramic coatings on the surface of $2 \mathrm{~A} 12 \mathrm{Al}$ alloys in different conversion times. Obviously, a large number of micro-cracks were formed on the PCC coatings surface of all samples. This was due to dehydration of PCC ceramic coatings during the aging process in post-treatment. Moreover, with the extension of conversion time, the micro-crack of PCC coating became smaller and more uniform. Compared with the ceramic coatings prepared in each stage, they have their own characteristics. As shown in Fig. 2A, PCC ceramic coating displayed "bark-like" surface morphology with a small number of flats formed on the partial activated sites of $2 \mathrm{~A} 12 \mathrm{Al}$ substrate surface when sample was put in conversion solution for $10 \mathrm{~min}$. After chemical conversion treatment for $30 \mathrm{~min}$, the PCC coating showed a like dry-land structure which consisted with numerous micro-blocks (Fig. 2D) because of the growth of grains and the increased of new crystal nucleus. While prolonging the conversion time to $60 \mathrm{~min}$, grain almost covered the whole Al substrate surface (Fig. 2G and H). Meanwhile, compared with coating formed
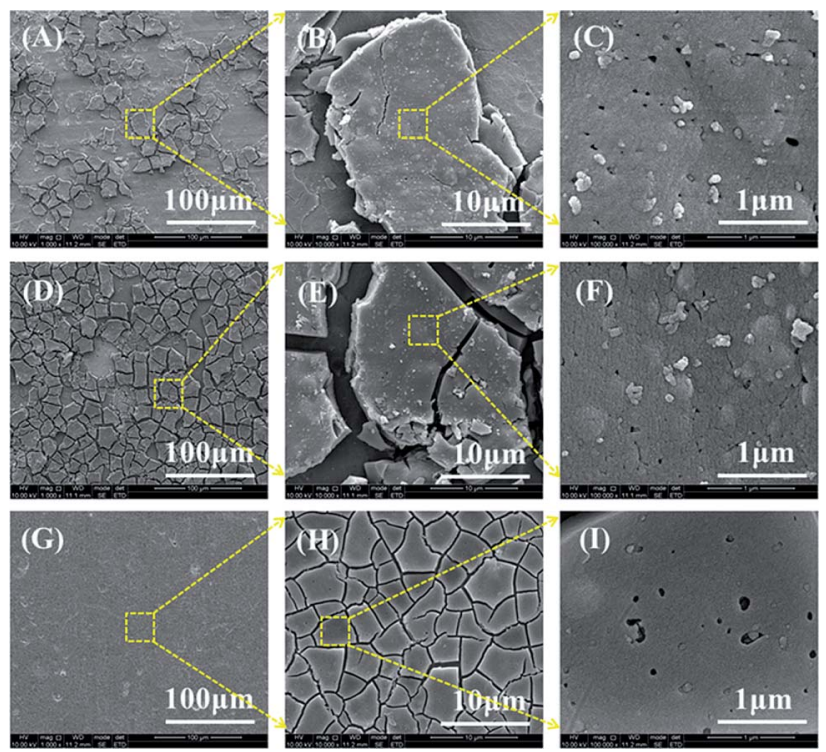

Fig. 2 Surface morphologies of PCC ceramic coatings on the surface of 2A12 Al alloys formed in different conversion times: $10 \mathrm{~min}(\mathrm{~A}-\mathrm{C})$, 30 min (D-F) and 60 min (G-I). with short conversion time (Fig. 2C and F), the ceramic coatings (Fig. 2I) fabricated with long conversion time were smoother and denser because of the increase of fine grains. In addition, lots of irregular nano-pores (about $50 \mathrm{~nm}$ ) exist on the surface of ceramic coatings of each sample, because of hydrogen escaping. In fact, the growth mode of PCC ceramic coatings was nucleation-growth process, namely, insoluble phosphate crystals nucleated preferentially at defective locations such as grain boundaries and dislocations in the Al alloy (Fig. 2A), and then it spread around and growth (Fig. 2D), eventually the entire surface would be completely covered (Fig. 2G).

The cross-section morphologies of PCC ceramic coating prepared with different conversion times were presented in Fig. 3. It was observed that the thickness of PCC ceramic coatings increased gradually with the prolongation of conversion time, and the thickness of PCC coating was about $800 \mathrm{~nm}, 2 \mu \mathrm{m}$ and $4 \mu \mathrm{m}$, respectively. Fig. 3A and D showed cross-section morphologies of PCC coating formed at $10 \mathrm{~min}$, there were no micro-cracks between ceramic coating and Al substrate, and close integration each other. Cross-section morphologies of PCC coating prepared at $30 \mathrm{~min}$ (Fig. 3B and E) were rough, and the distribution of ceramic coating was very non-uniform. When the conversion time reached $60 \mathrm{~min}$, PCC coating became more homogeneous (Fig. S1 $\dagger$ ). Besides, it could be seen that the ceramic coatings have a tendency of outward-inward bidirectional growth, which indicated that Al substrate was dissolved during the growth process of PCC ceramic coating.

\subsection{Chemical elements of PCC ceramic coatings}

Fig. 4 showed energy dispersive spectra of PCC ceramic coatings with treatment of $60 \mathrm{~min}$. The surface morphology of PCC ceramic coatings prepared at $60 \mathrm{~min}$ was shown in Fig. 4A. Meanwhile, it could be seen from the mapping-EDS of PCC coating (Fig. 4B-F) that compositions of PCC ceramic coating were mainly composed of $\mathrm{O}, \mathrm{Al}, \mathrm{P}, \mathrm{Cr}$ and trace $\mathrm{F}$ elements. Moreover, the $\mathrm{O}, \mathrm{P}, \mathrm{Cr}$ and $\mathrm{F}$ elements distribute homogeneously on PCC ceramic coating surface. While Al was the main element in the substrate, which indicated that both substrate
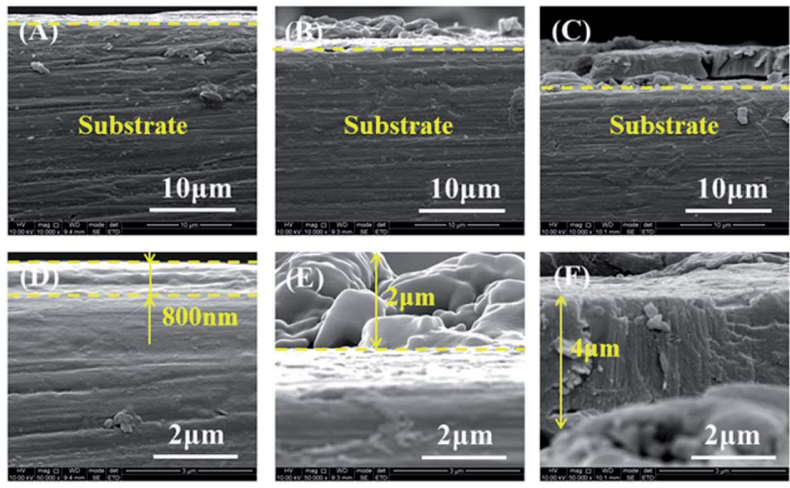

Fig. 3 Cross-section morphologies of PCC ceramic coatings prepared with different conversion time: $10 \mathrm{~min}(A$ and $D), 30 \mathrm{~min}$ ( $B$ and $\mathrm{E}$ ) and $60 \mathrm{~min}(\mathrm{C}$ and $\mathrm{F}$ ). 

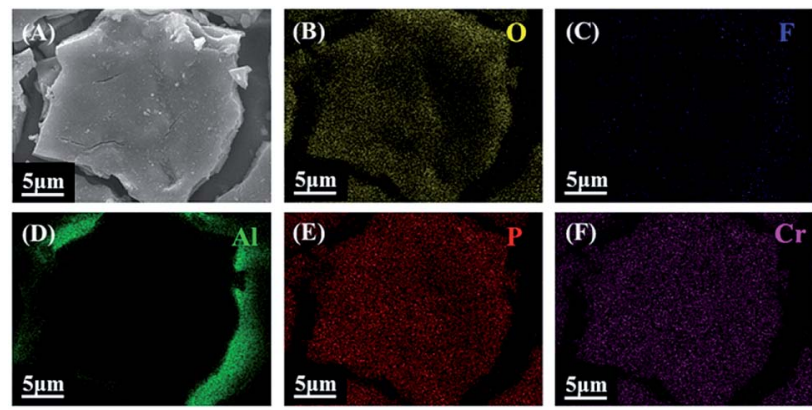

Fig. 4 (A) Surface morphology of PCC coatings with treatment of 60 min; (B)-(F) surface elemental mapping-EDS of $\mathrm{O}, \mathrm{F}, \mathrm{Al}, \mathrm{P}, \mathrm{Cr}$ elements of coated sample.

and oxidation solution promoted the formation of PCC ceramic coating.

Cross-sectional morphology and lineal-EDS analysis of PCC coatings formed on $2 \mathrm{~A} 12 \mathrm{Al}$ alloy were shown in Fig. 5. Apparently, PCC ceramic coating with thickness of about $4 \mu \mathrm{m}$ was bonded well with the $2 \mathrm{~A} 12 \mathrm{Al}$ substrate (Fig. 5A). Fig. 5B displayed cross-section lineal-EDS of $\mathrm{O}, \mathrm{F}, \mathrm{Al}, \mathrm{P}$ and $\mathrm{Cr}$ elements of PCC coatings. It could be seen that all elements have some small random fluctuations. This phenomenon was attributed to the micro-pore in the coating. Furthermore, the content of $\mathrm{Al}$ element decreased gradually from $\mathrm{Al}$ substrate to the surface of PCC ceramic coating, which indicated that Al element was from $2 \mathrm{~A} 12 \mathrm{Al}$ substrate. Moreover, the variation trend of $\mathrm{O}, \mathrm{P}$ and $\mathrm{Cr}$ element was the same, namely, their first increased gradually, then stabilized and finally decreased gradually from Al substrate to the surface of PCC ceramic coating. This indicated that $\mathrm{O}, \mathrm{P}$ and $\mathrm{Cr}$ elements were from conversion solution. In addition, $\mathrm{F}$ element existed only in trace amounts in the PCC coating, and it has little change from $\mathrm{Al}$ substrate to the surface of PCC ceramic coating.

\subsection{Chemical phases of PCC ceramic coatings}

XRD patterns of the bare $2 \mathrm{~A} 12 \mathrm{Al}$ alloy and PCC ceramic coatings (formed after 60 min treatments) were illustrated in Fig. 6. As could be seen, XRD patterns of bare $2 \mathrm{~A} 12 \mathrm{Al}$ alloy and coated
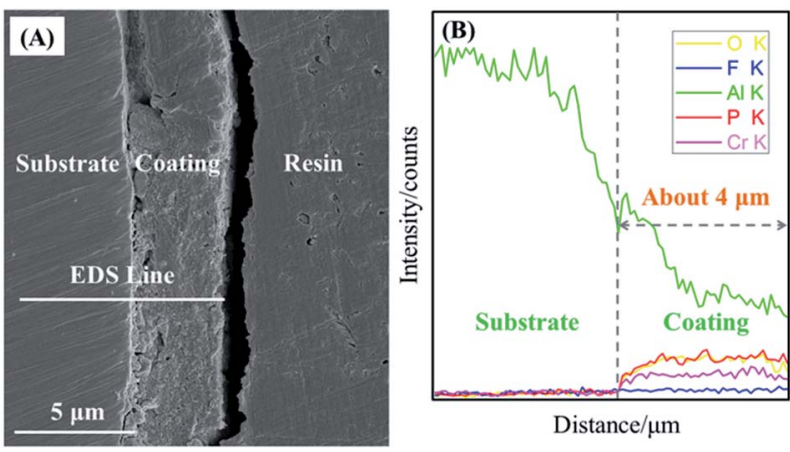

Fig. 5 (A) Cross-sectional morphology of PCC coatings prepared at 60 min and (B) cross-section lineal-EDS of $\mathrm{O}, \mathrm{F}, \mathrm{Al}, \mathrm{P}$ and $\mathrm{Cr}$ elements of PCC coatings.

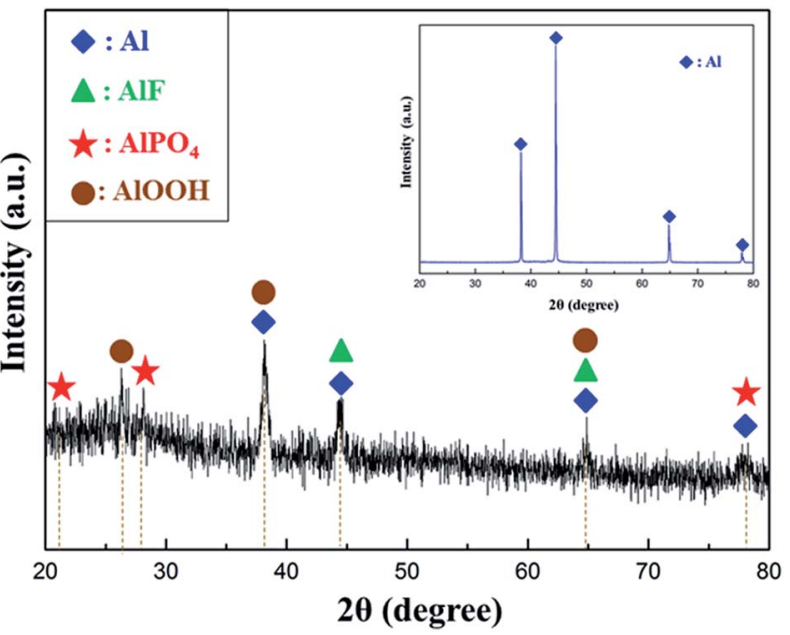

Fig. 6 XRD patterns of PCC ceramic coatings prepared on the surface of 2A12 Al alloy at 60 min (the inset was XRD patterns of 2A12 Al alloy substrate).

$2 \mathrm{~A} 12 \mathrm{Al}$ alloy has obvious differences. For the bare $2 \mathrm{~A} 12 \mathrm{Al}$ alloy (inset), only the diffraction peaks of $\mathrm{Al}$ were characterized, which because the naturally formed oxide film on the surface of $2 \mathrm{~A} 12 \mathrm{Al}$ alloy substrate was too thin to be broken down to the $\mathrm{Al}$ substrate via X-ray. By comparison, the prominent diffraction peaks displayed that PCC ceramic coatings were mainly composed of $\mathrm{Al}, \mathrm{AlF}_{3}, \mathrm{AlOOH}$ and $\mathrm{AlPO}_{4}$ phase. Diffraction peaks of Al phase were also detected owing to the porosity of PCC ceramic coatings. In the meantime, there was obvious amorphous phase in the XRD patterns of the ceramic coatings. This suggested that the ceramic coatings fabricated on the surface of $2 \mathrm{~A} 12 \mathrm{Al}$ alloy had a low crystallinity or a thin coating thickness.

\subsection{Chemical valence of PCC ceramic coatings}

The elemental contents and chemical compositions of PCC ceramic coatings prepared on the surface of $2 \mathrm{~A} 12 \mathrm{Al}$ alloy were further elucidated with XPS spectra. Fig. 7 displayed the full spectrum of PCC ceramic coating and high resolution spectra of each element. The full spectra (Fig. 7A) exhibited signals of C, O, $\mathrm{F}, \mathrm{Al}, \mathrm{P}$ and $\mathrm{Cr}$. Thereinto, it was clear that $\mathrm{C} 1 \mathrm{~s}$ (binding energy $=285.0 \mathrm{eV}$ ) peak could be found, for one thing, because the carbon was used as reference peak for other spectra; for another, it could also be ascribed to accidental contamination while transfer of the specimen in air. ${ }^{44,45}$ Other elements were consistent with the mapping-EDS (Fig. 4) and lineal-EDS results (Fig. 5). The atomic percent for O, F, Al, P and $\mathrm{Cr}$ in PCC ceramic coatings were obtained via XPS spectrum and shown in Table 2 (the extraneous carbon element was not included).

Fig. 7B showed the high resolution spectrum of oxygen, and the $\mathrm{O} 1 \mathrm{~s}$ spectrum peak observed at $531.3 \mathrm{eV}$ could be due to $\mathrm{P}-\mathrm{O}$ of $\mathrm{PO}_{4}{ }^{3-}$ and $\mathrm{O}-\mathrm{H}$ of $\mathrm{OH}^{-} .{ }^{46}$ The oxygen peak of metal oxide that appeared about $530 \mathrm{eV}$ could not be found, which indicated that the absence of any metal oxides in PCC ceramic coating. Moreover, for the F 1s (Fig. 7C), only one peak could be observed at $685.4 \mathrm{eV}$, which attribute to $\mathrm{AlF}_{3} \cdot{ }^{47}$ Fig. $7 \mathrm{D}$ showed the XPS 

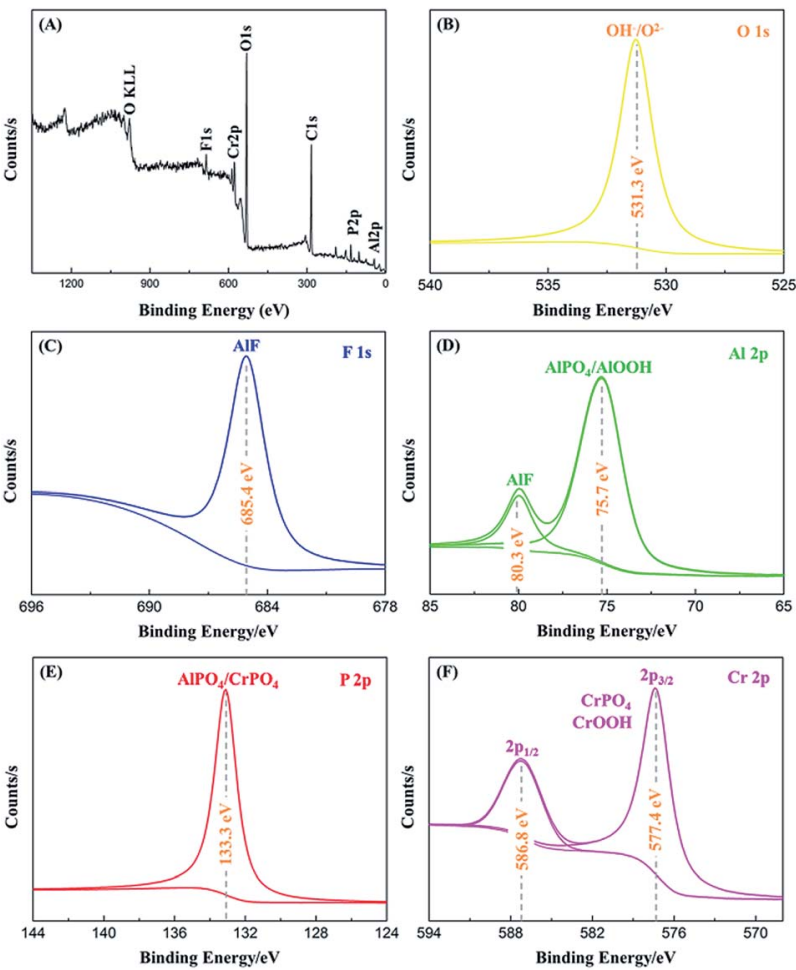

Fig. 7 XPS spectra of 2A12 Al alloys coated with PCC ceramic coating: (A) survey spectra and high resolution (B) O 1s, (C) F 1s, (D) Al 2p, (E) P $2 p$, (F) $\mathrm{Cr} 2 \mathrm{p}$ core level spectra.

Table 2 Elemental contents of PCC ceramic coatings prepared on the surface of 2A12 Al alloy obtained via XPS spectrum

\begin{tabular}{llllll}
\hline Elements & $\mathrm{Al}$ & $\mathrm{O}$ & $\mathrm{P}$ & $\mathrm{Cr}$ & $\mathrm{F}$ \\
\hline at\% & 9.67 & 69.49 & 8.87 & 5.30 & 6.67
\end{tabular}

spectra of $\mathrm{Al} 2 \mathrm{p}$, where the peaks at $75.7 \mathrm{eV}$ and $80.3 \mathrm{eV}$, which suggested the presence of $\mathrm{Al}^{3+}$ as in $\mathrm{AlF}_{3}, \mathrm{AlOOH}$ and $\mathrm{AlPO}_{4}$, respectively. Meanwhile, the symmetric $\mathrm{P} 2 \mathrm{p}$ peak could be detected at $133.3 \mathrm{eV}$, which was characteristic of $\mathrm{PO}_{4}{ }^{3+} \cdot{ }^{1}$ In addition, the $\mathrm{Cr} 2 \mathrm{p}$ spectra (Fig. 7F) displayed a nice resolve spin orbit doublet with two peaks ( $\mathrm{Cr} 2 \mathrm{p}_{3 / 2}$ and $\mathrm{Cr} 2 \mathrm{p}_{1 / 2}$ ). The energy spacing between $\mathrm{Cr} 2 \mathrm{p}_{1 / 2}(586.8 \mathrm{eV})$ and $\mathrm{Cr} 2 \mathrm{p}_{3 / 2}(577.4 \mathrm{eV})$ was $9.4 \mathrm{eV}$, indicating the existence of chromate. For the $\mathrm{Cr} 2 \mathrm{p}_{3 / 2}$, the peak at $577.4 \mathrm{eV}$ was ascribed to $\mathrm{CrPO}_{4}$ and $\mathrm{CrOOH}{ }^{48}$

\subsection{Performance of PCC ceramic coatings}

3.5.1 Thermal stability. The thermal stability of PCC ceramic coatings were investigated via TG-DSC. Fig. 8 demonstrated the TG-DSC curves of PCC ceramic coatings measured in Ar with a heating rate of $10{ }^{\circ} \mathrm{C} \mathrm{min}^{-1}$. As it can be seen from TGDSC curves, less weight loss indicated that PCC ceramic coatings had excellent thermal stability (Table S1 $\dagger$ ). For green curve (DTG), there were two peaks which indicated that PCC ceramic coatings have loss weight for twice. From the red curve (mass) in Fig. 8, it was clear that PCC ceramic coating had first weight loss

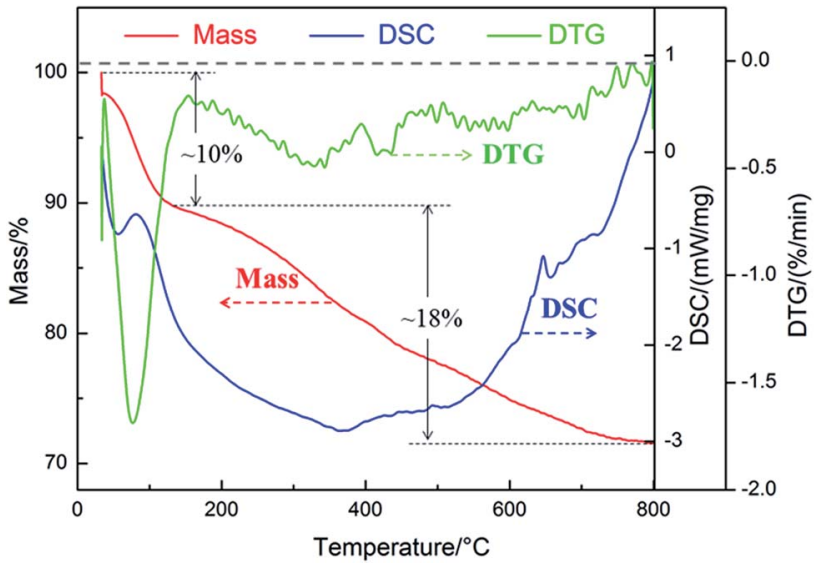

Fig. 8 TG-DSC curves in Ar of PCC ceramic coatings prepared on the surface of $2 \mathrm{~A} 12 \mathrm{Al}$ alloy.

of $10 \%$ from $30{ }^{\circ} \mathrm{C}$ to $110{ }^{\circ} \mathrm{C}$, which attributed to the loss of crystalline water in PCC ceramic coatings. For the blue curve, DSC illustrated that this process was endothermic. Furthermore, PCC ceramic coating also exhibited second weight loss (about $18 \%$ ) from $110{ }^{\circ} \mathrm{C}$ to $800{ }^{\circ} \mathrm{C}$, which caused from the transition between amorphous crystalline or microcrystalline and crystalline ${ }^{49}$ meantime, this also proved the existence of amorphous or microcrystalline in the PCC ceramic coatings.

3.5.2 Adhesion strength. Fig. 9 showed the variation curves of acoustic emission intensity/loading force and surface scratch track morphology of PCC ceramic coatings after scratch test. The adhesion strength was evaluated via the critical load $\left(L_{\mathrm{C}}\right)$ which is the loading force value of first sharp peak in scratch test curve. As shown in Fig. 9A, the critical load of PCC ceramic coatings was $178.55 \mathrm{~N}$. Compared with critical load of other coatings, ${ }^{50-52}$ the PCC ceramic coating own the excellent adhesion strength (Table S2 $\dagger$ ), which could be explained as follows: in the first place, the $\mathrm{AlPO}_{4}, \mathrm{AlF}_{3}$ and $\mathrm{AlOOH}$ in PCC ceramic coating were bonding with Al substrate through strong chemical bond and physical means. In the second place, the alkaline etching in pretreatment process created a rougher surface was benefit for situ growth of PCC coating, which boosting the bond strength between coating and Al substrate. From Fig. 9B, with the increase of loading force, the scratch track of PCC ceramic

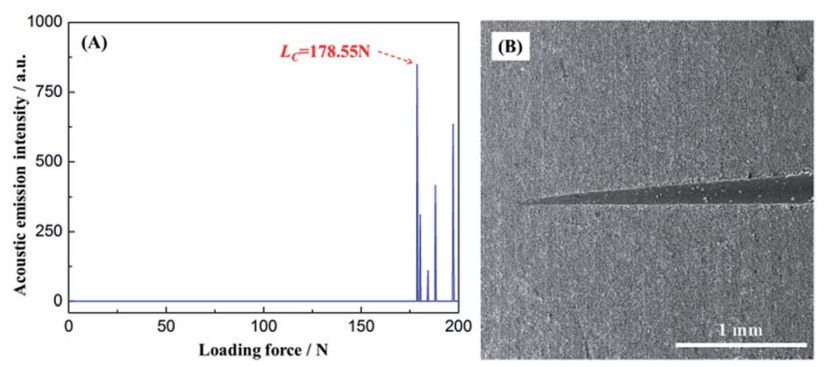

Fig. 9 Variation curves of acoustic emission intensity/loading force (A) and surface scratch track morphology of PCC ceramic coatings after scratch test (B). 
coating became wider and deeper. Meanwhile, the microstructure of PCC ceramic coatings after scratch test was integrity and homogeneous, which could also ascribe to the excellent scratch resistance of PCC coating.

\subsubsection{Corrosion resistance}

(1) Potentiodynamic polarization. Fig. 10A displayed the potentiodynamic polarization curves of $2 \mathrm{~A} 12 \mathrm{Al}$ substrate without and with PCC ceramic coatings in $3.5 \mathrm{wt} \% \mathrm{NaCl}$ aqueous solution. It could be seen that the slope of anode branch was higher than that of cathode branch for all samples, which indicated that $2 \mathrm{~A} 12 \mathrm{Al}$ substrate and PCC ceramic coatings were protected from the evolution of hydrogen reaction. For more clarification, the corrosion current density ( $\left.I_{\text {corr }}\right)$, corrosion potential $\left(E_{\text {corr }}\right)$ and corrosion inhibition efficiency $(\eta)$ were calculated using Tafel extrapolation method from the potentiodynamic polarization curves, and obtained data were tabulated in Table S3. $\dagger$ Obviously, the $I_{\text {corr }}$ of $2 \mathrm{~A} 12 \mathrm{Al}$ substrate and PCC ceramic coatings were $1.603 \times 10^{-4} \mathrm{~A} \mathrm{~cm}^{-2}$ and 1.382 $\times 10^{-7} \mathrm{~A} \mathrm{~cm}^{-2}$, separately. Compared with $2 \mathrm{~A} 12 \mathrm{Al}$ substrate, the $I_{\text {corr }}$ of PCC ceramic coatings was three orders of magnitude smaller than that of $2 \mathrm{~A} 12 \mathrm{Al}$ substrate, which revealed PCC ceramic coatings has lower corrosion rate. Moreover, it could be seen that the $E_{\text {corr }}$ of PCC ceramic coatings $(-1.099 \mathrm{~V})$ was more positive than that of $2 \mathrm{~A} 12 \mathrm{Al}$ substrate $(-1.264 \mathrm{~V})$. The decrease of $I_{\text {corr }}$ and increase of $E_{\text {corr }}$ of PCC ceramic coatings indicated the remarkable enhancement of anti-corrosion resistance of coatings owning to uniform and compact microstructure. What's more, corrosion inhibition efficiency $(\eta)$ of PCC ceramic coating was calculated by eqn (1). ${ }^{53}$ Thereinto, where $I_{\text {corr }}{ }^{m}$ and $I_{\text {corr }}{ }^{n}$ were the corrosion current density of without and with PCC ceramic coating, respectively. It's worth noticing that $\eta$ could reach as high as $99.91 \%$ which also indicated the excellent corrosion resistance performance of coating.

$$
\eta=\frac{I_{\text {corr }}{ }^{m}-I_{\text {corr }}{ }^{n}}{I_{\text {corr }}^{m}} \times 100 \%
$$
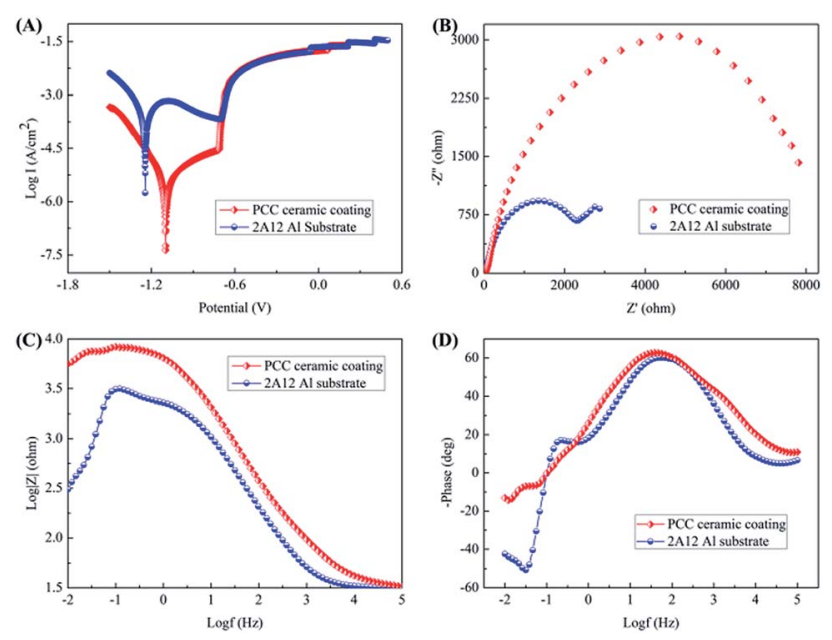

Fig. 10 Potentiodynamic polarization curves (A), Nyquist plot (B), Bode modulus (C) and phase (D) plots of 2A12 Al substrate without and with PCC ceramic coatings.
(2) Electrochemical impedance spectroscopy (EIS). EIS measurements were conducted to further evaluate the effect of PCC ceramic coating on the anti-corrosion performance of 2A12 Al substrate. Fig. 10B showed the Nyquist plots of $2 \mathrm{~A} 12 \mathrm{Al}$ substrate and PCC ceramic coatings, obviously, both samples displayed one single semicircle, which inferred that chargetransfer occurred between sample and electrolyte solution. ${ }^{54}$ The Nyquist plot of $2 \mathrm{~A} 12 \mathrm{Al}$ substrate presented one semicircle with a tail in the low-frequency region, which was related to the diffusion of electrolyte. Meanwhile, the semicircle diameter of PCC ceramic coatings was much larger than that of $2 \mathrm{~A} 12 \mathrm{Al}$ substrate, indicating PCC ceramic coatings owned higher polarization resistance and lower corrosion rate, this further confirmed that PCC ceramic coating have better corrosion resistance than $2 \mathrm{~A} 12 \mathrm{Al}$ substrate. Moreover, the Bode-module and Bode-phase plots could be seen in Fig. 10C and D. The impedance modulus in low frequency region also has an effect on total corrosion protection performance. As shown in Fig. 10C, the impedance modulus of PCC ceramic coating was always greater than that of $2 \mathrm{~A} 12 \mathrm{Al}$ substrate, which meant that PCC ceramic coatings could provide remarkable corrosion protection for $2 \mathrm{~A} 12 \mathrm{Al}$ substrate. Besides, the Bode-phase plot (Fig. 10D) demonstrated two time constants for $2 \mathrm{~A} 12 \mathrm{Al}$ substrate and three time constants for PCC ceramic coatings in low frequency and medium-high frequency region. By comparison, PCC ceramic coatings owned higher phase angle at middle-high frequency, which revealed that PCC ceramic coatings own good dielectric characteristic.

In general, it could be concluded that PCC ceramic coatings demonstrated a fantastic corrosion resistance performance. This phenomenon could be attributed to the existence of crystalline $\mathrm{AlPO}_{4} / \mathrm{AlF}_{3} / \mathrm{AlOOH}$ and amorphous $\mathrm{CrPO}_{4} / \mathrm{CrOOH}$ as barrier layer which provided an insulator between the external environment and 2A12 Al substrate. Moreover, amorphous phase without defects was not susceptible to corrosion, and $\mathrm{CrOOH}$ was easily decomposed into $\mathrm{Cr}_{2} \mathrm{O}_{3}$, which was also beneficial to enhance the corrosion resistance of PCC ceramic coating.

\subsection{Film-forming mechanism of PCC ceramic coatings}

The formation of PCC ceramic coatings was not only a chemical reaction, but also a sophisticated micro electrochemical reaction. ${ }^{37}$ Nevertheless, there was still no reasonable mechanism to explain PCC ceramic coatings formation process. In the present study, the film-forming mechanism of PCC ceramic coatings was investigated, the schematic illustration of the formation process of PCC coatings on $2 \mathrm{~A} 12 \mathrm{Al}$ alloys samples surface was shown in Fig. 11. The growth process included the following four stages.

Stage I: dissolution of $2 \mathrm{~A} 12 \mathrm{Al}$ substrate and hydrogen evolution (Fig. 11A). In this stage, Al substrate and the oxide of aluminum surface were dissolved, which owing to the presence of phosphoric acid and hydrofluoric acid in the oxidation solution (eqn (2)-(5)). Simultaneously, this process was accompanied with the release of hydrogen (eqn (3) and (4)). This 

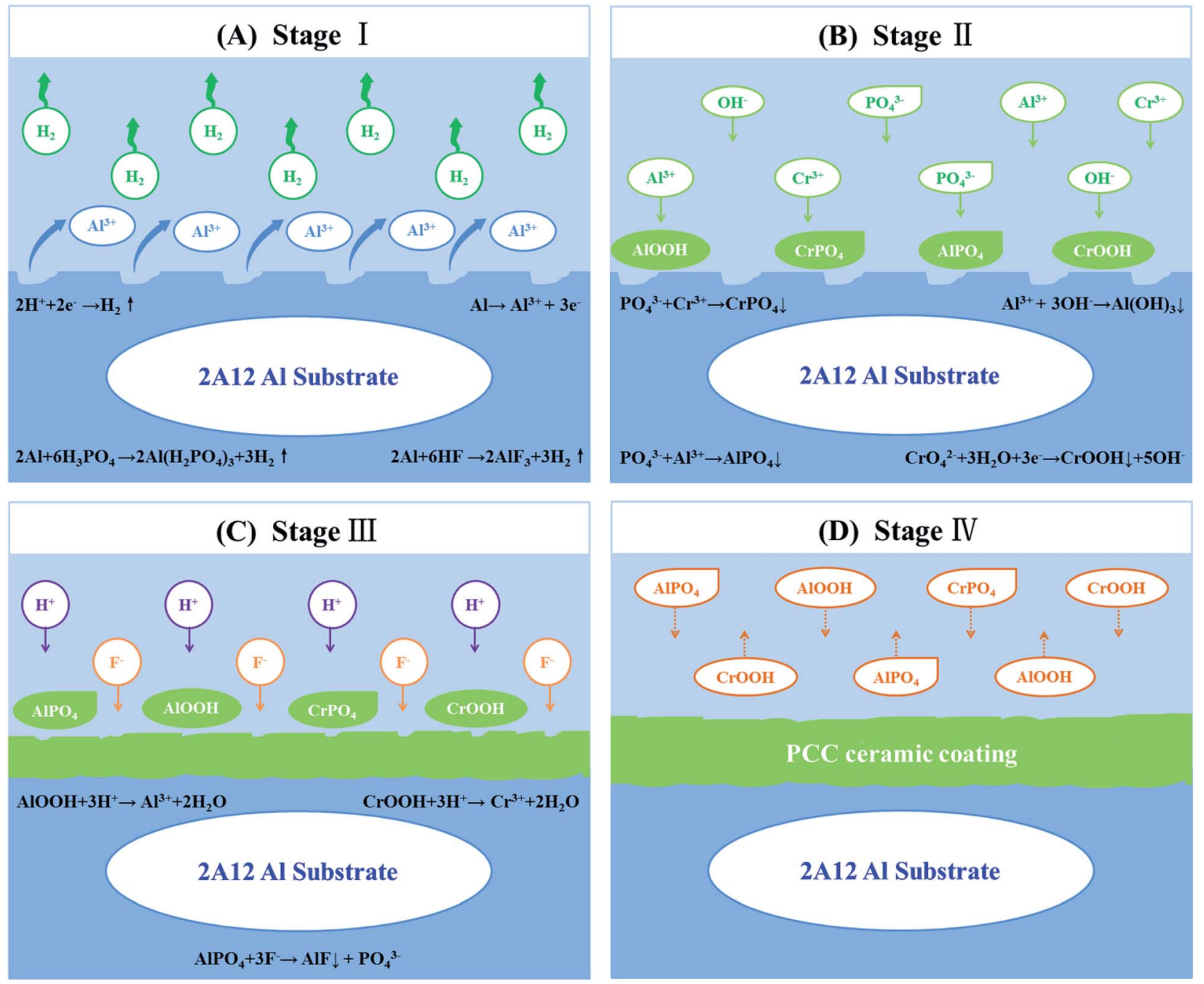

Fig. 11 Schematic illustration of the formation process of PCC ceramic coatings on 2A12 Al alloys samples. (A) Dissolution of 2A12 Al substrate and hydrogen evolution. (B) Crystallization of insoluble phosphates and formation of amorphous phase. (C) Growth of insoluble phosphates and dissolution of PCC ceramic coatings. (D) Growth and dissolution of PCC coatings to dynamic equilibrium.

process could also be attributed to ionization of $\mathrm{Al}, \mathrm{H}_{2} \mathrm{O}$ and $\mathrm{H}^{+}$ of micro electrochemical reaction, causing the dissolution of $\mathrm{Al}$ in the anode and hydrogen evolution from the cathode (eqn (6)$(8))$.

$$
\begin{gathered}
\mathrm{NaF}+\mathrm{H}_{3} \mathrm{PO}_{4} \rightarrow \mathrm{HF}+\mathrm{NaH}_{2} \mathrm{PO}_{4} \\
2 \mathrm{Al}+6 \mathrm{H}_{3} \mathrm{PO}_{4} \rightarrow 2 \mathrm{Al}\left(\mathrm{H}_{2} \mathrm{PO}_{4}\right)_{3}+3 \mathrm{H}_{2} \uparrow \\
2 \mathrm{Al}+6 \mathrm{HF} \rightarrow 2 \mathrm{AlF}_{3} \downarrow+3 \mathrm{H}_{2} \uparrow \\
\mathrm{Al}_{2} \mathrm{O}_{3}+6 \mathrm{HF} \rightarrow 2 \mathrm{AlF}_{3} \downarrow+3 \mathrm{H}_{2} \mathrm{O} \\
\mathrm{Al} \rightarrow \mathrm{Al}^{3+}+3 \mathrm{e}^{-} \\
2 \mathrm{H}^{+}+2 \mathrm{e}^{-} \rightarrow \mathrm{H}_{2} \uparrow \\
2 \mathrm{H}_{2} \mathrm{O}+2 \mathrm{e}^{-} \rightarrow \mathrm{H}_{2} \uparrow+2 \mathrm{OH}^{-}
\end{gathered}
$$

Stage II: crystallization of insoluble phosphates and the formation of amorphous phase (Fig. 11B). With the dissolution of aluminum and consumption of hydrogen ions in the first stage, hydrogen ions in oxidation solution could not diffuse rapidly to the surface of $\mathrm{Al}$ substrate, thus the $\mathrm{pH}$ value of aluminum surface increased, which resulting in the formation of amorphous phase and crystal nuclei of insoluble phosphate (eqn (9)-(14)). Meanwhile, nuclei were more likely to form preferentially where defects (grain boundary and dislocation) occurred. In fact, amorphous phases were formed on the surface of Al substrate before the formation of insoluble phosphate nuclei. ${ }^{55}$ XRD patterns of PCC ceramic coatings with poor crystallinity (Fig. 6) could be proved the existence of amorphous phase. It was that the deposition rate of the amorphous phase was so fast that it could not be observed easily.

$$
\begin{gathered}
2 \mathrm{CrO}_{3}+\mathrm{H}_{2} \mathrm{O} \rightarrow \mathrm{H}_{2} \mathrm{Cr}_{2} \mathrm{O}_{7} \\
\mathrm{H}_{2} \mathrm{Cr}_{2} \mathrm{O}_{7}+\mathrm{H}_{2} \mathrm{O} \rightarrow 2 \mathrm{CrO}_{4}{ }^{2-}+4 \mathrm{H}^{+}
\end{gathered}
$$




$$
\begin{gathered}
\mathrm{CrO}_{4}{ }^{2-}+3 \mathrm{H}_{2} \mathrm{O}+3 \mathrm{e}^{-} \rightarrow \mathrm{CrOOH} \downarrow+5 \mathrm{OH}^{-} \\
\mathrm{Cr}(\mathrm{OH})_{3}+\mathrm{H}_{3} \mathrm{PO}_{4} \rightarrow \mathrm{CrPO}_{4} \downarrow+3 \mathrm{H}_{2} \mathrm{O} \\
\mathrm{Al}^{3+}+\mathrm{PO}_{4}^{3-} \rightarrow \mathrm{AlPO}_{4} \downarrow \\
\mathrm{Al}^{3+}+3 \mathrm{OH}^{-} \rightarrow \mathrm{Al}(\mathrm{OH})_{3} \downarrow
\end{gathered}
$$

Stage III: growth of insoluble phosphates and dissolution of PCC ceramic coatings (Fig. 11C). With the prolongation of oxidation time, the insoluble phosphates grains grow up gradually, and new crystal nuclei of insoluble phosphate continuously formed on the Al substrate surface. However, fluoride ions could selectively dissolve aluminum phosphate to form aluminum fluoride, which leading to ceramic coating dissolution (eqn (15)). Besides, free-acids in the conversion solution also dissolved part of PCC ceramic coatings (eqn (16) and (17)).

$$
\begin{aligned}
& \mathrm{AlPO}_{4}+3 \mathrm{~F}^{-} \rightarrow \mathrm{AlF}_{3} \downarrow+\mathrm{PO}_{4}{ }^{3-} \\
& \mathrm{Al}(\mathrm{OH})_{3}+3 \mathrm{H}^{+} \rightarrow \mathrm{Al}^{3+}+3 \mathrm{H}_{2} \mathrm{O} \\
& \mathrm{CrOOH}+3 \mathrm{H}^{+} \rightarrow \mathrm{Cr}^{3+}+2 \mathrm{H}_{2} \mathrm{O}
\end{aligned}
$$

Stage IV: growth and dissolution of PCC coatings to dynamic equilibrium (Fig. 11D). During this period, both the partial dissolution of PCC coating and the formation and growth of new phosphate crystals were carried out simultaneously. Both crystallization dissolution and recrystallization dynamic reactions occurred in this process. As the reaction went on, the dissolution rate and recrystallization rate of phosphate crystals tend to be achieved dynamic equilibrium, the thickness of PCC coatings almost did not change, and PCC ceramic coatings were completely formed at this moment.

\section{Conclusions}

In summary, we have successfully fabricated PCC ceramic coatings with excellent microstructure, corrosion resistance and high temperature resistance on the surface of $2 \mathrm{~A} 12 \mathrm{Al}$ substrate via a simple and low cost chemical conversion process. SEM results showed that PCC ceramic coating had a homogeneous and compact microstructure with a few nano-pores $(\sim 50 \mathrm{~nm})$. EDS results indicated that the coating was predominantly composed of $\mathrm{Al}, \mathrm{O}, \mathrm{F}, \mathrm{Cr}$ and $\mathrm{P}$ element. XRD and XPS confirmed that the chemical composition of PCC coatings was $\mathrm{AlPO}_{4}$, $\mathrm{AlOOH}, \mathrm{AlF}_{3}$ and some amorphous phases $\left(\mathrm{CrPO}_{4}\right.$ and $\left.\mathrm{CrOOH}\right)$. Meanwhile, we found that PCC ceramic coatings own excellent thermal stability by TG-DSC analysis. Besides, the coatings exhibited remarkable adhesion strength $(178.55 \mathrm{~N})$ due to the strong chemical bond between PCC ceramic coating and 2A12 Al substrate and the increase of surface roughness. And PCC ceramic coating could effectively boost the corrosion resistance of $2 \mathrm{~A} 12 \mathrm{Al}$ substrate owing to the existence of crystalline $\mathrm{AlPO}_{4} /$ $\mathrm{AlF}_{3} / \mathrm{AlOOH}$ and amorphous $\mathrm{CrPO}_{4} / \mathrm{CrOOH}$ as barrier layer. Additionally, the film-forming mechanism of PCC ceramic coatings on the surface of $2 \mathrm{~A} 12 \mathrm{Al}$ substrate was discussed detailedly.

\section{Conflicts of interest}

There are no conflicts to declare.

\section{Acknowledgements}

This work was supported by the Chunhui Project of Education Ministry of China (No. Z2011074 and Z2015093). The Innovation Fund of Postgraduate of Xihua University (No. ycjj2018009). The Key Project of Natural Science Foundation of Sichuan Provincial Education Department (No. 16ZA0148), and the "Xihua Scholars" program of Xihua University (No. DC1900007152).

\section{References}

1 S. Shanmugam, K. Ravichandran, T. S. N. S. Narayanan and M. H. Lee, RSC Adv., 2015, 5, 988-1008.

2 R. Faria, P. Marques, P. Moura, F. Freire, J. Delgado and A. T. de Almeida, Renewable Sustainable Energy Rev., 2013, 24, 271-287.

3 H. C. Kim and T. J. Wallington, Environ. Sci. Technol., 2013, 47(12), 6089-6097.

4 J. Y. Zhang, X. H. Shi and B. J. Fei, Int. J. Fatigue, 2012, 38, 144-154.

5 J. Yan, X. Y. Zeng, M. Gao, J. Lai and T. X. Lin, Appl. Surf. Sci., 2009, 255, 7307-7313.

6 Z. H. Zhang, W. Y. Li, J. F. Li and Y. J. Chao, Int. J. Adv. Manuf. Technol., 2014, 73, 1213-1218.

7 Z. L. Liu, H. T. Cui, S. D. Ji, M. Q. Xu and X. C. Meng, J. Mater. Sci. Technol., 2016, 32, 1372-1377.

8 Z. Y. Wang, T. Ma, W. Han and G. C. Yu, Trans. Nonferrous Met. Soc. China, 2007, 17, 326-334.

9 F. Yang, G. H. Wu, D. L. Sun and H. Shao, Mater. Sci. Eng., A, 2000, 280, 50-53.

10 H. S. Gugtapeh, K. Jafarzadeh, Z. Valefi and S. M. Mirali, Surf. Coat. Technol., 2018, 349, 846-857.

11 P. Wang, T. Wu, Y. T. Xiao, L. Zhang, J. Pu, W. J. Cao and X. M. Zhong, Vacuum, 2017, 142, 21-28.

12 M. Kaseem, Y. H. Lee and Y. G. Ko, Mater. Lett., 2016, 182, 260-263.

13 J. H. Wang, M. Hu. Du, F. Z. Han and J. Yang, Appl. Surf. Sci., 2014, 292, 658-664.

14 L. Wen, Y. M. Wang, Y. Jin, B. Liu, Y. Zhou and D. B. Sun, Surf. Coat. Technol., 2013, 228, 92-99.

15 H. Zhang, R. F. Luo, W. J. Li, J. Wang, M. F. Maitz, J. Wang, G. J. Wan, Y. Q. Chen, H. Sun, C. X. Jiang, R. Shen and N. Huang, Corros. Sci., 2015, 94, 305-315.

16 Y. Wang, L. D. Sun, C. J. Xiang, X. L. Zhao, S. J. Wu and S. Zhang, Corros. Sci., 2017, 124, 193-197.

17 S. Ide, Ö. Ö. Çapraz, P. Shrotriya and K. R. Hebert, Electrochim. Acta, 2017, 232, 303-309.

18 J. Wang, S. Huang, M. Y. He, P. H. Wangyang, Y. F. Lu, H. J. Huang and L. Xu, Ceram. Int., 2018, 44, 7656-7662.

19 P. Wang, T. Wu, Y. T. Xiao, J. Pu, X. Y. Guo, J. Huang and C. L. Xiang, J. Mater. Eng. Perform., 2016, 25, 3972-3976. 
20 W. Tillmann, D. Kokalj and D. Stangier, Surf. Coat. Technol., 2018, 344, 223-232.

21 D. H. Zhang and D. J. Kong, J. Alloys Compd., 2018, 735, 1-12.

22 K. Hili, D. Fan, V. A. Guzenko and Y. Ekinci, Microelectron. Eng., 2015, 141, 122-128.

23 D. Crouse, J. Simon, K. L. Schulte, D. L. Young, A. J. Ptak and C. E. Packard, Thin Solid Films, 2018, 649, 154-159.

24 A. I. Ryabchikov, E. B. Kashkarov, N. S. Pushilina, M. S. Syrtanov, A. E. Shevelev, O. S. Korneva, A. N. Sutygina and A. M. Lider' , Appl. Surf. Sci., 2018, 439, 106-112.

25 Q. K. Jiang, C. L. Qin, K. Amiya, S. Nagata, A. Inoue, R. T. Zheng, G. A. Cheng, X. P. Nie and J. Z. Jiang, Intermetallics, 2008, 16, 225-229.

26 E. J. Bird, K. A. Nelson, J. N. Harb and D. R. Wheeler, Electrochim. Acta, 2012, 70, 69-75.

27 X. C. Ma, N. Lun and S. L. Wen, Diamond Relat. Mater., 2005, 14, 68-73.

28 Y. F. Liao, Q. Xie, Q. Q. Xiao, Q. Chen, M. H. Fan, J. Xie, J. Huang, J. M. Zhang, R. Ma, S. L. Wang, H. X. Wu and D. Fang, Appl. Surf. Sci., 2017, 403, 302-307.

29 H. J. Zheng, J. H. Zhong, W. Wang, Y. F. Zheng and C. N. Ma, Thin Solid Films, 2008, 516, 4983-4987.

30 A. Kouadri and L. Barrallier, Mater. Sci. Eng., A, 2006, 429, 11-17.

31 A. Viswanathan, D. Sastikumar, H. Kumar and A. K. Nath, Opt. Laser Eng., 2012, 50, 1321-1329.

32 R. C. Zeng, Y. Hu, F. Zhang, Y. D. Huang, Z. L. Wang, S. Q. Li and E. H. Han, Trans. Nonferrous Met. Soc. China, 2016, 26, 472-483.

33 G. Q. Duan, L. X. Yang, S. J. Liao, C. Y. Zhang, X. P. Lu, Y. G. Yang, B. Zhang, Y. Wei, T. Zhang, B. X. Yu, X. C. Zhang and F. H. Wang, Corros. Sci., 2018, 135, 197-206.

34 C. C. Jiang, G. Y. Xiao, X. Zhang, R. F. Zhu and Y. P. Lu, New J. Chem., 2016, 40, 1347-1353.

35 H. Y. Su and C. S. Lin, Corros. Sci., 2014, 83, 137-146.

36 X. C. Zhao, G. Y. Xiao, X. Zhang, H. Y. Wang and Y. P. Lu, J. Phys. Chem. C, 2014, 118(4), 1910-1918.

37 B. Liu, G. Y. Xiao, C. C. Jiang, Y. Z. Zheng, L. L. Wang and Y. P. Lu, RSC Adv., 2016, 6, 75365-75375.
38 X. Zhang, G. Y. Xiao, Y. Jiao, X. C. Zhao and Y. P. Lu, Surf. Coat. Technol., 2014, 240, 361-364.

39 H. Y. Chen, E. L. Zhang and K. Yang, Mater. Sci. Eng., C, 2014, 34, 201-206.

40 H. Zhao, S. Cai, Z. T. Ding, M. Zhang, Y. Li and G. H. Xu, RSC Adv., 2015, 5, 24586-24590.

41 C. X. Zhang, Y. Y. Jia, X. Zhong, X. S. Wu and Y. L. Liu, RSC Adv., 2016, 6, 62045-62051.

42 J. A. Treverton and N. C. Davies, Met. Technol., 1977, 4, 480489.

43 M. Golabadi, M. Aliofkhazraei, M. Toorani and A. S. Rouhaghdam, J. Ind. Eng. Chem., 2017, 47, 154-168.

44 T. Lostak, A. Maljusch, B. Klink, S. Krebs, M. Kimpel, J. Flock, S. Schulz and W. Schuhmann, Electrochim. Acta, 2014, 137, 65-74.

45 M. Eslami, M. Fedel, G. Speranza, F. Deflorian, N. E. Andersson and C. Zanella, Electrochim. Acta, 2017, 255, 449-462.

46 Y. Chen, B. L. Luan, G. L. Song, Q. Yang, D. M. Kingston and F. Bensebaa, Surf. Coat. Technol., 2012, 210, 156-165.

47 A. E. Hughes, R. J. Taylor and B. R. W. Hinton, Surf. Interface Anal., 1997, 25, 223-234.

48 X. Zhang, W. G. Sloof, A. Hovestad, E. P. M. van Westing, H. Terryn and J. H. W. de Wit, Surf. Coat. Technol., 2005, 197, 168-176.

49 Y. F. Pan, X. Wang, S. B. Zhang, Y. Wang and J. T. Huang, Surf. Coat. Technol., 2016, 302, 131-141.

50 X. L. Shi, H. M. Zhu and A. Valanezhad, Phys. Status Solidi A, 2018, 215, 1800143.

51 C. C. Jiang, G. Y. Xiao and X. Zhang, New J. Chem., 2016, 40, 1347-1353.

52 S. X. Wang, X. H Liu and L. Q. Wang, RSC Adv., 2017, 7, 16078-16086.

53 Y. Liu, S. Y. Li, J. J. Zhang, J. A. Liu, Z. W. Han and L. Q. Ren, Corros. Sci., 2015, 94, 190-196.

54 B. D. Mert, Corros. Sci., 2016, 103, 88-94.

55 E. L. Ghali and R. J. A. Potvin, Corros. Sci., 1972, 12, 583-594. 